\title{
ANALISIS KANDUNGAN LOGAM BERAT MERKURI (Hg) DAN TIMBAL (Pb) \\ PADA KOSMETIK LIPSTIK YANG BEREDAR DI KOTA MAKASSAR DENGAN METODE SPEKTROFOTOMETRI SERAPAN ATOM
}

\author{
Nurmaya Effendi, Mamat Pratama, Husna Kamaruddin
}

Fakultas Farmasi Universitas Muslim Indonesia

Email : nurmayaeffendi@yahoo.co.id.

\begin{abstract}
Lipstick is a lip cosmetic that almost every day is used by the most women. Lipstick should be safe and does not contain hazardous materials as it can go ingested with food or drink consumed. One of hazardous contaminants in lipstick is contained heavy metals, such as lead and mercury. Based on these considerations, the cosmetic lipstick should be safe and do not contain harmful ingredients, One of the parameters to determine the lipstick cosmetics are safe or not from the content of the metals in contained. To determine the metals $\mathrm{Pb}$ and $\mathrm{Hg}$ contamination in cosmetics lipsticks do research by doing destruction samples and proceed with the analysis of the metal content using atomic absorption spectrophotometry. The results showedthat inallfour samplesstudiedlipstickall containmercury $(\mathrm{Hg})$ levelseachwithA0.0460 $\mu \mathrm{g} / \mathrm{g}, B 0.0425 \mu \mathrm{g} / \mathrm{g}, C 0.0345 \mu \mathrm{g} / \mathrm{g}$, andD0,0431 $\mu \mathrm{g} / \mathrm{g}$, as wellasfor lead(Pb) levelseachwithA6.1628 $\mu \mathrm{g} / \mathrm{g}$, B3.5041 $\mu \mathrm{g} / \mathrm{g}$, C56.6496 $\mu \mathrm{g} / \mathrm{g}$, andD6.0324 $\mu \mathrm{g} / \mathrm{g}$.
\end{abstract}

Key words : Lipstick, Mercury $(\mathrm{Hg})$, Lead $(\mathrm{Pb})$, SSA (Atomic Absorption Spectrophotometry)

\section{PENDAHULUAN}

Kosmetik berasal dari kata Yunani 'kosmetikos' yang mempunyai arti keterampilan menghias atau mengatur. Pengertian kosmetik dalam Peraturan Menkes RI no 445 tahun 1998 dijelaskan sebagai berikut :

"Kosmetika adalah bahan atau campuran bahan untuk digosokkan, dilekatkan, dituangkan, dipercikkan atau disemprotkan pada, dimasukkan dalam, dipergunakan pada badan atau bagian badan manusia dengan maksud untuk membersihkan, memelihara, menambah daya tarik atau mengubah rupa, melindungi supaya tetap dalam keadaan baik memperbaiki bau badan tetapi tidak dimaksudkan untuk mengobati atau luar dari sediaan kosmetika dengan keharusan pengisian nomor ijin edar dari Departemen Kesehatan (Anonim, 1992).

Kosmetika sudah dikenal manusia sejak berabad-abad yang lalu, dan baru abad ke-19 mendapat 
Analisis Kandungan Logam Berat Merkuri Dan Timbale Pada Kosmetik Lipstik Yang Beredar Di Kota Makassar Dengan Metode Spektrofotometri Serapan Atom

perhatian khusus, yaitu selain untuk kecantikan juga mempunyai fungsi untuk kesehatan. Perkembangan ilmu kosmetik serta industrinya baru di mulai secara besar-besaran pada abad ke-20 dan kosmetik menjadi salah satu bagian dari dunia usaha. Dewasa ini, teknologi kosmetik begitu maju dan merupakan panduan antara kosmetik dan obat (pharmaceutical) atau dikenal dengan istilah kosmetik medic (cosmeceuticals) (Iswari dan Tranggono, 2007).

Selain obat dan makanan yang banyak beredar, ribuan macam kosmetika juga ditawarkan di pasaran dengan berbagai cara sehingga menimbulkan keinginan orang untuk memakainya. Tetapi, tidak jarang pemakaian kosmetika tersebut bukannya mempercantik kulit, melainkan malah menjadikan kulit rusak. Beberapa bahan berbahaya yang dilarang digunakan dalam produk kosmetik tetapi masih banyak beredar di masyarakat di antaranya merkuri (air raksa atau $\mathrm{Hg}$ ), hidroquinon lebih dari $2 \%$, zat warna rhodamin $B$, methanil yellow dan merah K.3. Bahan-bahan ini sebetulnya telah dilarang penggunaannya sejak tahun 1998 melalui Peraturan Menteri Kesehatan $\mathrm{RI}$ No.445/Menkes/Per/V/1998. Pada tahun 2007, Badan POM berhasil menemukan 44 jenis produk kosmetika, yang mengandung zat pewarna terlarang, tanpa izin edar dan menggunakan bahan berbahaya, diantaranya Diethylen Glycol (DEG), merkuri atau air raksa $(\mathrm{Hg})$, hidroquinon, tretinoin atau asam retionat dan pewarna $\mathrm{K} 3$ yang merupakan pewarna sintetis yang sering digunakan pada kertas dan tekstil (Irmawati, 2007).

Berdasarkan hasil penelitian terhadap bedak tabur produk dalam negeri dan produk luar negeri yang dilakukan oleh Supriadi pada tahun 2008 mengandung logam $\mathrm{Pb}$ dan Cr.Penelitian yang telah dilakukan oleh Livia pada tahun 2011 menunjukkan bahwa pada krim kosmetik yang diteliti semuanya mengandung logam merkuri. Penelitian oleh Renita pada tahun 2007 dengan hasil menunjukkan bahwa terkandung logam berat $\mathrm{Hg}$, $\mathrm{Cd}$, dan $\mathrm{Pb}$ dalam lipstik dan krim pemutih yang melebihi ambang batas penggunaan yang ditetapkan oleh balai POM dan Peraturan Menteri Kesehatan RI No. 445/Menkes/Per/V/1998. Benita(2012) menyatakan bahwa data yang didapat tidak ada perbedaan signifikan antara lipstik teregistrasi baik yang berasal dari dalam maupun luar negeri di 
Analisis Kandungan Logam Berat Merkuri Dan Timbale Pada Kosmetik Lipstik Yang Beredar Di Kota Makassar Dengan Metode Spektrofotometri Serapan Atom

daerah Jakarta Selatan dan dari keenam merek lipstik yang diuji, semuanya mengandung timbal melebihi persyaratan yang ditetapkan oleh BPOM yaitu kurang dari $20 \mathrm{mg} / \mathrm{kg}$ Kandungan logam berat yang kecil dalam suatu bahan sukar diketahui atau ditentukan keberadaanya dengan pereaksipereaksi kimia pada umumnya, tetapi dapat diketahui keberadaanya dengan spektrofotometri serapan atom (Gunanjar, 1985).

Efek merkuri yang terakumulasi, akan mengakibatkan keracunan sistemik jika digunakan dalam jangka panjang, meskipun efeknya belum akan terasa dalam hitungan hari. Akibatnya, kerap kali konsumen tidak merasakan efek samping yang merugikan ini (Darmono, 1995).

Paparan timbal untuk jangka panjang dapat menyebabkan kerusakan ginjal dan sakit perut. Timbal dapat mempengaruhi hampir setiap organ dan sistem dalam tubuh, dan efek dari timbal yang masuk lewat pernapasan sama dengan yang masuk karena ditelan.

Sediaan kosmetik kemungkinan ada yang tidak melalui prosedur produksi, dan biasanya yang dicurigai adalah hasil industri rumah tangga yang memproduksi kosmetik tidak memiliki ijin dari Balai Pengawasan Obat dan Makanan. Hal ini akan menyebabkan suatu sediaan kosmetik akan mengandung bahan yang dilarang oleh Badan Pengawasan Obat dan Makanan (BPOM), sehingga bila sampai ke masyarakat akan sangat berbahaya bagi kesehatan. Efek bagi kesehatan bila pemakaian bahan tersebut adalah terjadi iritasi kulit, serta bila terpapar dalam jumlah besar dan pemakaian dalam jangka waktu yang panjang akan menyebabkan kanker kulit.

Berdasarkan hasil investigasi dari Badan Pengawas Obat dan Makanan (BPOM) masih banyak ditemukan sediaan kosmetik yang tidak memenuhi standar yang ditetapkan Departemen Kesehatan Republik Indonesia.

\section{METODE PENELITIAN}

\section{Jenis dan Desain Penelitian}

Jenis penelitian ini dilakukan secara eksperimental

\section{Alat dan Bahan}

Alat yang digunakan adalah botol vinkleir BOD, corong, gelas kimia, labu ukur $50 \mathrm{~mL}$ dan $100 \mathrm{~mL}$, pipet volume $5 \mathrm{~mL}$.

Bahan yang digunakan adalaha air suling, asam nitrat pekat $\left(\mathrm{HNO}_{3}\right)$, kertas whatman No. 41, sampel lipstick. 
Analisis Kandungan Logam Berat Merkuri Dan Timbale Pada Kosmetik Lipstik Yang Beredar Di Kota Makassar Dengan Metode Spektrofotometri Serapan Atom

\section{Prosedur kerja}

\section{Penyiapan Sampel}

Pengambilan sampel

Sampel lipstik diambil di kota Makassar dengan harga di bawah Rp. 25.000 dikeluarkan dari kemasannya kemudian disimpan di gelas kimia.

\section{Penyiapan sampel}

Sampel yang diambil, kemudian ditimbang dan disimpan di lemari asam untuk dilakukan pemanasan.

\section{Penyiapan Larutan Sampel}

Ditimbang masing-masing 2 gram (lipstik), kemudian dimasukkan kedalam gelas kimia, setelah itu ditambahkan $\mathrm{HNO}_{3} 15 \mathrm{~mL}$, dan dipanaskan di lemari asam pada suhu $95^{\circ} \mathrm{C}$ sampai uap kuning hilang dan menjadi jernih, kemudian dicukupkan volume standar dengan menambahkan akuades hingga 100 $\mathrm{mL}$, dan disaring dengan kertas whatman No. 41 , kemudian dilakukan analisis data.

\section{Metode Analisis}

Penetapan kadar logam $\mathrm{Hg}$ secara spektrofotometri serapan atom

Pembuatan larutan stok $\mathrm{Hg} 1000$ ppm

Dilarutkan $1000 \mathrm{mg}$ logam merkuri di dalam $20 \mathrm{~mL}$ asam nitrat 5 M, kemudian diencerkan dengan akuadest dalam labu tentukur $1 \mathrm{~L}$ hingga garis tanda

\section{Pembuatan kurva baku $\mathrm{Hg}$}

Larutan baku 1000 ppm, dipipet masing-masing $1 \mathrm{~mL}, 2 \mathrm{~mL}, 3 \mathrm{~mL}, 4$ $\mathrm{mL}$, dan $5 \mathrm{~mL}$, dicukupkan volumenya hingga tanda di dalam labu tentukur $100 \mathrm{~mL}$, dan diperoleh konsentrasi 10 ppm, 20 ppm, 30 ppm, 40 ppm, dan 50 ppm

\section{Pengukuran logam $\mathrm{Hg}$}

Alat Spektrofotometri Serapan Atom diatur pada panjang gelombang $258,65 \mathrm{~nm}$, dalam keadaan nyala udara asetilen diaspirasikan air dan alat pengukur dijadikan nol, dan secara berturut-turut diaspirasikan larutan baku menurut bertambahnya konsentrasi, kemudian nilai absorban baku dicatat, dan dibuat persamaan garis regresi linear dari absorban hasil pengukuran standar, absorban hasil pengukuran contoh dimasukkan ke dalam persamaan regresi linear sehingga diperoleh konsentrasi contoh, dan prosedur diatas diulangi sebanyak dua kali.

Penetapan kadar logam $\mathrm{Pb}$ secara spektrofotometri serapan atom.

\section{Pembuatan larutan stok 1000 ppm}

Dilarutkan logam timbal 1000 $\mathrm{mg}$ di dalam $50 \mathrm{~mL}$ asam nitrat $2 \mathrm{M}$, kemudian diencerkan dengan akuadest dalam labu tentukur $1 \mathrm{~L}$ hingga garis tanda. 
Analisis Kandungan Logam Berat Merkuri Dan Timbale Pada Kosmetik Lipstik Yang Beredar Di Kota Makassar Dengan Metode Spektrofotometri Serapan Atom

\section{Pembuatan Kurva Baku Pb}

Larutan baku 1000 ppm, dipipet sebanyak $5 \mathrm{~mL}$ dan dimasukkan ke dalam labu tentukur $50 \mathrm{~mL}$ dan dicukupkan volumenya hingga tanda batas untuk mendapatkan 100 ppm. Selanjutnya dari larutan baku 100 ppm dipipet $5 \mathrm{~mL}$ dan diencerkan sebanyak $50 \mathrm{~mL}$ untuk mendapatkan 10 ppm, kemudian dari 10 ppm dibuat beberapa variasi konsentrasi dengan memipet masing-masing $1 \mathrm{~mL}, 2 \mathrm{~mL}, 3$ $\mathrm{mL}, \quad 4 \mathrm{~mL}$, dan $5 \mathrm{~mL}$, untuk mendapatkan konsentrasi 0,1 ppm, 0,2 ppm, 0,3 ppm, 0,4 ppm, dan 0,5 ppm

\section{Pengukuran Logam Pb}

Alat Spektrofotometri Serapan Atom diatur pada panjang gelombang 283,3 $\mathrm{nm}$, dalam keadaan nyala udara asetilen diaspirasikan air dan alat pengukur dijadikan nol, dan secara berturut-turut diaspirasikan larutan baku menurut bertambahnya konsentrasi, kemudian nilai absorban baku dicatat, dan larutan contoh kemudian diaspirasikan kedalam nyala yang sebelumnya telah diaspirasikan dengan air suling untuk menolkan alat, kemudian dibuat persamaan garis regresi linear dari absorban hasil pengukuran standar, dan absorban hasil pengukuran contoh dimasukkan ke dalam persamaan regresi linear sehingga diperoleh konsentrasi contoh, kemudian prosedur diatas diulangi sebanyak dua kali.

\section{Pengumpulan Data}

Data diperoleh dari hasil pengukuran kadar logam $\mathrm{Hg}$ dan $\mathrm{Pb}$ dalam kosmetik lipstik dengan menggunakan

Spektrofotometri Serapan Atom (SSA). Dari hasil pengukuran serapan larutan baku pada panjang gelombang tertentu dibuat grafik untuk masing-masing logam. Untuk menarik garis lurus pada grafik antara serapan dengan konsentrasi ini perlu bantuan persamaan regresi. Sumbu $X$ adalah konsentrasi dalam bpj sedangkan sumbu $Y$ adalah nilai serapan $(A)$.

\section{HASIL PENELITIAN}

Tabel 1. Hasil perhitungan regresi analisis kandungan merkuri $(\mathrm{Hg})$ pada kosmetik lipstik yang beredar dikota Makassar secara spektrofotometri serapan atom pada panjang gelombang 258,65 nm.

\begin{tabular}{ccc}
\hline No & Konsentrasi $(\mathbf{p p m})$ & Absorbansi \\
\hline 1 & 10 & 0.1147 \\
2 & 20 & 0.2888 \\
3 & 30 & 0.4283 \\
4 & 40 & 0.6038 \\
5 & 50 & 0.7161 \\
\hline
\end{tabular}


Analisis Kandungan Logam Berat Merkuri Dan Timbale Pada Kosmetik Lipstik Yang Beredar Di Kota Makassar Dengan Metode Spektrofotometri Serapan Atom

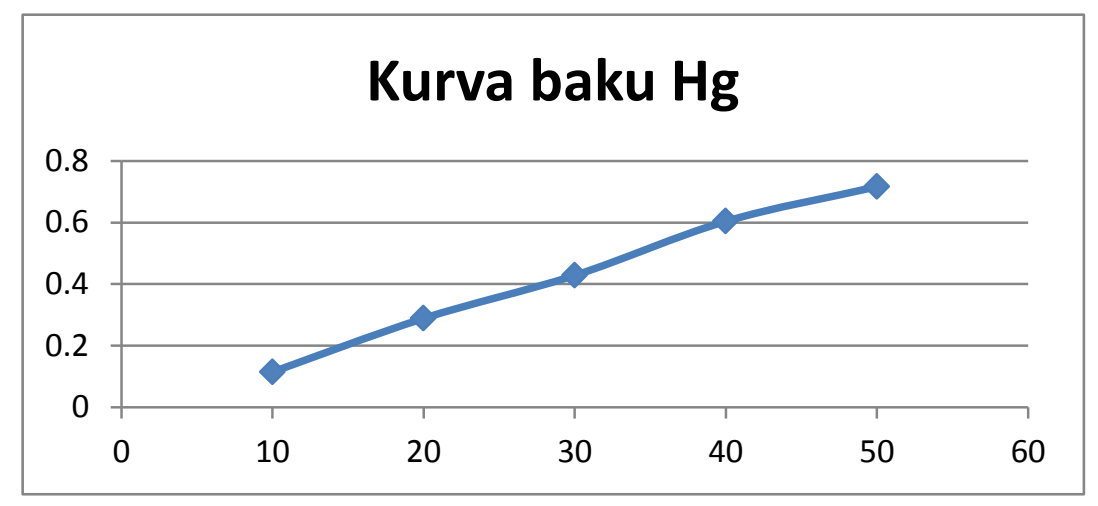

Persamaan regresinya adalah: $Y=-0.025+0,0151 \times$ dengan $r=0,9977$

Gambar 1. Kurva kalibrasi pada elemen merkuri $(\mathrm{Hg})$.

Tabel 2. Hasil perhitungan regresi analisis kandungan timbal (Pb) pada kosmetik lipstik yang beredar dikota Makassar secara spektrofotometri serapan atom pada panjang gelombang $283,3 \mathrm{~nm}$.

\begin{tabular}{ccc}
\hline No & Konsentrasi (ppm) & Absorbansi \\
\hline 1 & 0,1 & 0,0046 \\
2 & 0,5 & 0,0135 \\
3 & 1,0 & 0,0270 \\
4 & 1,5 & 0,0402 \\
5 & 2,0 & 0,0534 \\
\hline
\end{tabular}

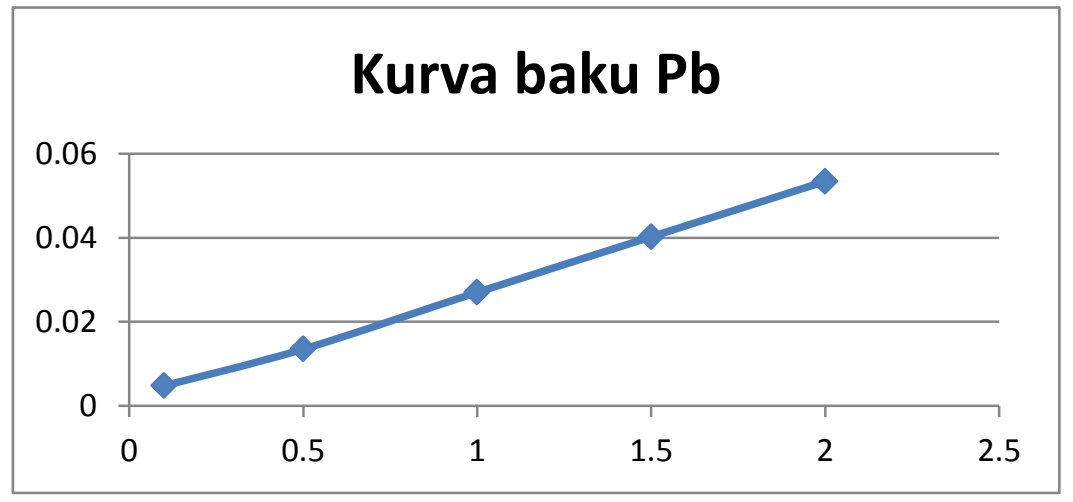

Persamaan regresinya adalah: $Y=0,0014+0,0258 x$, dengan $r=0,9995$

Gambar 2. Kurva kalibrasi pada elemen timbal (Pb). 
Analisis Kandungan Logam Berat Merkuri Dan Timbale Pada Kosmetik Lipstik Yang Beredar Di Kota Makassar Dengan Metode Spektrofotometri Serapan Atom

Tabel 3. Hasil pengukuran kosmetik lipstik pada logam merkuri $(\mathrm{Hg})$ dan timbal $(\mathrm{Pb})$

\begin{tabular}{ccc}
\hline Sampel & Kadar Hg $(\mu \mathbf{g} / \mathbf{g})$ & Kadar $\mathbf{P b}(\boldsymbol{\mu g} / \mathbf{g})$ \\
\hline A & 0,0460 & 6,1628 \\
B & 0,0425 & 3,5041 \\
C & 0,0345 & 56,6496 \\
D & 0,0431 & 6,0324 \\
\hline
\end{tabular}

\section{PEMBAHASAN}

Penelitian ini dilakukan dengan menganalisis kandungan logam berat merkuri $(\mathrm{Hg})$ dan timbal $(\mathrm{Pb})$ yang terdapat pada kosmetik lipstik yang beredar di kota Makassar dengan metode spektrofotometri serapan atom (SSA). Penelitian ini bertujuan untuk menentukan kandungan logam berat merkuri $(\mathrm{Hg})$ dan timbal $(\mathrm{Pb})$ sebagai bahan tambahan dalam pembuatan kosmetik lipstik.

Lipstik merupakan kosmetik bibir yang digunakan oleh sebagian besar wanita dan hampir setiap hari digunakan. Lipstik harus aman dan tidak mengandung bahan-bahan berbahaya karena dapat ikut tertelan bersama makanan atau minuman yang dikonsumsi. Salah satu cemaran berbahaya yang terdapat dalam lipstik adalah logam berat, seperti merkuri dan timbal.

Metode yang digunakan dalam pengambilan sampel yaitu metode sampling pemilihan salah satu sampel yang akan diujikan, kemudian sampel ditimbang dimasukkan kedalam gelas kimia, ditambahkan $15 \mathrm{~mL}$ asam nitrat. Kemudian dipanaskan $95^{\circ} \mathrm{C}$ selama 5 jam, kemudian ditepatkan volume akhir (standar) dengan menambahkan air suling lalu dipanaskan sampai mendidih kemudian dilakukan penyaringan dan dilanjutkan pengukuran kadar logam berat merkuri dan timbal menggunakan spektrofotometri serapan atom (SSA) pada panjang gelombang untuk merkuri 258,65 $\mathrm{nm}$ dan timbal 283,3 $\mathrm{nm}$.

Berdasarkan hasil pengukuran kadar logam berat merkuri dan timbal pada kosmetik lipstik menggunakan spektrofotometri serapan atom pada panjang gelombang 258,65 $\mathrm{nm}$ di peroleh hasil kadar logam merkuri pada sampel A 0,0460 $\mu \mathrm{g} / \mathrm{g}$, sampel $B$ $0,0425 \mu \mathrm{g} / \mathrm{g}$, sampel C $0,0345 \mu \mathrm{g} / \mathrm{g}$, dan sampel $D$ adalah $0,0431 \mu \mathrm{g} / \mathrm{g}$, dan diperoleh hasil kadar timbal dengan panjang gelombang 283,3 $\mathrm{nm}$, pada sampel A 6,1628 $\mu \mathrm{g} / \mathrm{g}$, sampel B 3,5041 $\mu \mathrm{g} / \mathrm{g}$, sampel C 56,6496 $\mu \mathrm{g} / \mathrm{g}$, dan sampel D 6,0324 $\mu \mathrm{g} / \mathrm{g}$, dan dari peraturan permenkes ditetapkan 
Analisis Kandungan Logam Berat Merkuri Dan Timbale Pada Kosmetik Lipstik Yang Beredar Di Kota Makassar Dengan Metode Spektrofotometri Serapan Atom

bahwa tidak boleh ada bahan tambahan merkuri dan timbal pada kosmetik lipstik.

Efek merkuri yang bersifat akumulasi ini, akan mengakibatkan keracunan sistemik jika digunakan dalam jangka panjang, meskipun efeknya belum akan terasa dalam hitungan hari. Akibatnya, kerap kali konsumen tidak merasakan efek sampingnya yang merugikan ini

Paparan timbal untuk jangka panjang dapat menyebabkan kerusakan ginjal dan sakit perut. Timbal dapat mempengaruhi hampir setiap organ dan sistem dalam tubuh, dan efek dari timbal yang masuk lewat pernapasan sama dengan yang masuk karena ditelan.

Merkuri $(\mathrm{Hg})$ dan timbal $(\mathrm{Pb})$ mulai dimanfaatkan dalam bidang kosmetik sebagai salah satu zat pembuatan sediaan kosmetik terutama pada lipstik karena logam tersebut dapat memberikan warna yang mengkilat dan cerah pada lipstik.

Berdasarkan peraturan badan pengawasan obat dan makanan tentang persyaratan cemaran logam berat pada kosmetik menyatakan bahwa merkuri $(\mathrm{Hg})$ tidak lebih dari 1 $\mathrm{mg} / \mathrm{kg}$ atau $1 \mathrm{mg} / \mathrm{L}$ (1 ppm), dan timbal $(\mathrm{Pb})$ tidak lebih dari $20 \mathrm{mg} / \mathrm{kg}$ atau 20 $\mathrm{mg} / \mathrm{L}$ (20 ppm).
Dengan hasil penelitian tersebut diharapkan kepada masyarakat dalam berhati-hati memilih kosmetik lipstik karena kemungkinan terdapat logam berat seperti merkuri $(\mathrm{Hg})$ dan timbal $\mathrm{Pb})$ yang mana logam tersebut sangat berbahaya apabila penggunaannya dalam jangka yang cukup lama.

\section{KESIMPULAN}

Berdasarkan hasil penelitian dapat disimpulkan bahwa semua kosmetik lipstik yang diuji mengandung logam merkuri $(\mathrm{Hg})$ dan timbal $(\mathrm{Pb})$, dari hasil penelitian semuanya memenuhi standar kecuali sampel $C$ untuk timbal.

\section{DAFTAR PUSTAKA}

Anonim. 1992. Undang-Undang Republik Indonesia No. 23 Tahun 1992 tentang Kesehatan. Jakarta: Departemen Kesehatan.

Benita, V. 2012. Analisis Cemaran Timbal Dalam Lipstik Yang Beredar Di Jakarta Selatan Secara Spektrofotometri Serapan Atom. Fakultas Farmasi. Universitas Pancasila

Darmono, 1995. Logam Berat dalam Sistem Biologi. UI Press. Jakarta.

Gunanjar, 1985, Spektrofotometer Serapan Atom, PPNY-Batan, Yogyakarta

Irmawati, 2007. Balai POM Memusnahkan Ratusan Jenis Obat dan Makanan Berbahaya, Tempo Interaktif 
Analisis Kandungan Logam Berat Merkuri Dan Timbale Pada Kosmetik Lipstik Yang Beredar Di Kota Makassar Dengan Metode Spektrofotometri Serapan Atom

Iswari,R.S., dan Tranggono, 2007. Buku Pegangan IImu Pengetahuan Kosmetik Dr. Gramedia Pustaka Utama Jakarta.

Livia. 2011. Pengujian Kandungan Merkuri Dalam Sediaan Kosmetik Dengan Spektrofotometri Serapan Atom. Program Studi Farmasi. Universitas Islam Bandung

Peraturan Menteri Kesehatan RI No.1176/Menkes/Per/VIII/2010 . "Tentang notifikasi kosmetik".

Peraturan Kepala Badan Pengawasan Obat Dan Makanan RI No. HK.03.1.23.07.11.6662 Tahun
2011. "Tentang persyaratan logam berat dalam kosmetik".

Renita, A. 2007. Analisis Konsentrasi Logam Berat Merkuri, Crom, Dan Timbal Dalam Sampel Kosmetik Lipstik Dan Krim Pemutih Dengan Metode Spektrofotometri serapan Atom. Fakultas Farmasi. Universitas Islam Indonesia

Supriyadi. 2008. Analisis Logam Timbal dan Krom Pada Bedak Tabur Secara Spektrofotometri Serapan Atom. Program Studi Farmasi. Universitas Setia Budi 